\title{
Disease and disaster: Navigating food insecurity in a community affected by crises during COVID-19
}

\author{
Andrew S. Pyle, ${ }^{a *}$ Michelle Eichinger, ${ }^{b}$ Barry A. \\ Garst, ${ }^{\mathrm{c}}$ Catherine Mobley, ${ }^{\mathrm{d}}$ Sarah F. Griffin, ${ }^{\mathrm{e}}$ \\ Leslie H. Hossfeld, ${ }^{\mathrm{f}}$ and Mike McGirr $\mathrm{g}$ \\ Clemson University
}

Helen R. Saunders ${ }^{h}$

Tri-County Technical College Commission

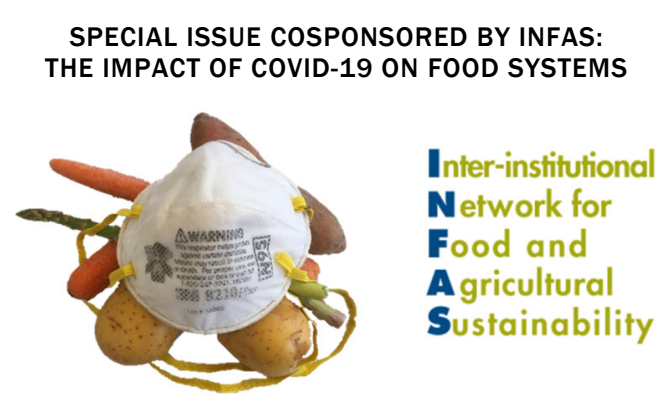

Submitted October 1, 2020 / Revised January 23 and March 4, 2021 / Accepted March 5, 2021 /

Published online May 11, 2021

Citation: Pyle, A. S., Eichinger, M., Garst, B. A., Mobley, C., Griffin, S. F., Hossfeld, L. H., McGirr, M., \& Saunders, H. R. (2021). Disease and disaster: Navigating food insecurity in a community affected by crises during COVID-19. Journal of Agriculture, Food Systems, and Community Development, 10(3), 37-54. https://doi.org/10.5304/jafscd.2021.103.005

Copyright (C) 2021 by the Authors. Published by the Lyson Center for Civic Agriculture and Food Systems. Open access under CC-BY license.

\begin{abstract}
This exploratory study examines how a community experiencing food insecurity while navigating multiple crises can be a model to inform resources, processes, and systems supporting communities facing similar circumstances. Data for this study were collected from residents of a community in Oconee County, a rural county in the northwest corner of South Carolina experiencing pervasive food insecurity. The community was severely impacted by the onset of COVID-19 and further

a * Corresponding author: Andrew S. Pyle, Associate Professor of Communication, Clemson University; 415 Strode Tower; Clemson, SC 29634 USA; +1-501-650-0943; apyle@,clemson.edu

${ }^{\mathrm{b}}$ Michelle Eichinger, Land Grant Local Research Fellow, Clemson University.

${ }^{\mathrm{c}}$ Barry A. Garst, Associate Professor of Youth Development Leadership, Clemson University.

${ }^{\mathrm{d}}$ Catherine Mobley, Professor of Sociology, Clemson

University.
\end{abstract}

devastated by a tornado in mid-April. The area of the county that sustained the greatest damage from the tornado was the Utica Mill Hill community, home to the county's most vulnerable population. This cascading series of events constituted a crisiswithin-a-crisis for the community. In this study, we sought to learn more about community members' experiences and the effects of the crises on community members' access to food. We conducted indepth interviews with 14 residents living in the Utica Mill Hill community. The results provided

\footnotetext{
e Sarah F. Griffin, Professor of Public Health Sciences, Clemson University.

${ }_{\mathrm{f}}$ Leslie H. Hossfeld, Professor \& Dean, College of Behavioral, Social, \& Health Sciences, Clemson University.

g Mike McGirr, Director, Land Grant Local, Clemson University.

${ }^{\mathrm{h}}$ Helen R. Saunders, Community Partner, Oconee County Representative for the Tri-County Technical College Commission.
} 
insight into community members' experiences of the crises and the nature of community-level response and recovery efforts. We learned about participants' experiences with food insecurity, new food policy developments, and gained unexpected insight into community members' experiences with mental health challenges related to the crises.

\section{Keywords}

COVID-19, Crisis, Food Insecurity, Food Systems, Mental Health, Pandemic, Resiliency, Tornado

\section{Introduction}

In 2020, the U.S. faced an unprecedented number of hazards, threats, emergencies, and crises. Regional and national-level emergencies have been particularly devastating, including wildfires across the West coast, tornadoes across the Midwest and Southeast, and hurricanes across the Southeast and along the entire East coast. These events, in a typical year, would have been record-setting challenges for communities to manage. However, 2020 was not a typical year. As of this writing, the U.S. is roughly one year into a global pandemic following the first cases of COVID-19 reported in the U.S. in January and February of 2020 (Jorden et al., 2020). While the nation was facing unprecedented natural disasters and attempting to manage a pandemic and its related significant negative health impacts—e.g., "worse mental health outcomes, increased substance use, and elevated suicidal ideation" (Czeisler et al., 2020, p. 1057)—other widespread crises developed. For example, families facing food insecurity found that due to the economic effects of the pandemic food resources became even scarcer, especially for families with the highest risk of poverty and food insecurity (Dev \& Kabir, 2020; Laborde et al., 2020).

To provide a window into communities facing multiple concurrent crises, this exploratory study focuses on a single neighborhood in Oconee County, South Carolina. This community is ideal for such a study for several reasons. First, even prior to 2020, members of this community were experiencing pervasive food insecurity. Second, the community was severely impacted by the onset of COVID-19, which thoroughly upended residents' daily lives. Third, the county was devastated by a tornado in mid-April 2020; the area sustaining the greatest damage was the Utica Mill Hill community, home to the county's most vulnerable population. Fourth, after the tornado parts of the community were affected by a public health crisis, a hepatitis A outbreak resulting from a lack of clean water. As these crises unfolded in the Utica Mill Hill community, community members began to report an increase in mental health-related challenges from the onset of COVID-19. As applied scholars representing a land-grant institution with a service-oriented mission, we believe that Utica Mill Hill presents a unique opportunity to develop knowledge that can support the residents, as well as other communities in the future facing food insecurity and extended crises. The background of these issues is explored in the subsequent sections, followed by a discussion of the study research questions.

\section{Food Insecurity}

The U.S. Department of Agriculture (USDA) defines food insecurity as a "household-level economic and social condition of limited or uncertain access to adequate food" (USDA, 2019). The official measure of food insecurity in the United States is established through the Current Population Survey Food Security Supplement (USDA Economic Research Service, 2020), in which respondents are asked 10 to 18 food security-related questions depending on family composition. Questions range from "We worried whether our food would run out before we got money to buy more" to "In the last 12 months did you or other adults in your household ever not eat for a whole day because there wasn't enough money for food?" (ColemanJensen et al., 2016, p. 3). During the Great Recession, food insecurity was exacerbated by rising inflation, increase in food costs, increases in unemployment, and the collapse in the price of housing. Early evidence suggests, however, that levels of food insecurity are even higher during the COVID-19 pandemic than during the Great Recession (Schanzenbeck \& Tomeh, 2020; U.S. Census Bureau, 2020).

\section{Food Deserts}

Food insecurity is often associated with living in a 
food desert, defined by Congress as "an area in the United States with limited access to affordable and nutritious food, particularly such an area composed of predominantly lower-income neighborhoods and communities" (Food, Conservation, and Energy Act of 2008). This definition addresses the complex interplay of cost, variety, decisional power, and nutritional quality influencing food security. Prolonged residence in areas of low access to healthful food and in "food swamps," areas of high access to energy-dense (highly processed) foods, may lead to higher rates of obesity and other diet-related diseases (Cooksey-Stowers et al., 2017; Danhong et al., 2016). This is especially troubling, as health care costs are almost 50 percent higher for food insecure households than food secure households (Tarasuk et al., 2015). While food deserts may not directly cause food insecurity, they do provide good indicators of areas where food insecurity is more likely.

Food insecurity and food deserts can be locally contextualized. For example, South Carolina has a food insecurity rate of $12.3 \%$, compared to $13 \%$ for the U.S. Oconee County has a food insecurity rate of $17.5 \%$ for families with children and has two USDA- designated food deserts, one of which is the site of our study (Feeding America, 2018). Local community food systems are not only about food production, they also provide a vehicle for economic development and honoring local food heritages and food culture (Hossfeld \& Rico Mendez, 2018).

\section{Crisis and Resilience: Community Response to Disaster}

Many residents in the study area are in a nearconstant state of crisis resulting from food insecurity. A crisis is characterized as a "specific, unexpected, and non-routine event or series of events that create high levels of uncertainty and simultaneously present an organization with both opportunities for and threats to its high priority goals" (Ulmer et al., 2019, p. 7). While Ulmer and colleagues focus on the impact of crises on organizations, crises often have a broader impact on entire communities (Anthony \& Sellnow, 2011; Pyle, 2018). This is especially true when considering the community-level effects of natural disasters.
Natural disasters. Natural disasters such as wildfires, earthquakes, and hurricanes are often devastating to communities, if not entire regions. Yet natural disasters create opportunities for renewal post-crisis, as communities seek to rebuild and re-establish normalcy (Ulmer et al., 2019). For example, the EF5 tornado that struck Greensburg, Kansas in May 2007 allowed very little time for the town to prepare and left almost no structures standing in the town of 1400 (Sommerfeld, 2015). Yet the Greensburg tornado demonstrated community resilience. After the devastation, the residents decided they would rebuild and restore their town. But rather than trying to rebuild what they had before the tornado, they decided to build a new, forward-looking, sustainable town. Tornadoes are distinct from other types of disasters in that they often affect small portions of a community, while other parts of the same community are unaffected or minimally affected. This was the case with the tornado that struck Oconee county in April 2020. The greatest damage ocurred in the Utica Mill Hill community. This renewal process is highly dependent on community resilience.

Resilience. Resilience is the "ability to recover the state of a system after it has been disrupted" (Anthony et al., 2019, p. 166). Community resilience, then, is a "community's ability to strengthen its response to deal with crises or disruptions ... [a resilient community can] bounce back from an event, not necessarily to return to normal, but to return to a new normal in the initial days, weeks, and months depending on the size and scope of the disaster" (Veil \& Bihop, 2014, p. 723).

Resilience is specifically tied to three aspects of efficacy: self-efficacy, system efficacy, and response efficacy. Self-efficacy is the ability of a person to implement some course of action to manage a risk or protect themself from harm (Witte et al., 2001). Self-efficacy is instilled within systems such as the "Run, Hide, Fight" heuristic for self-protection during an active shooter event (Ford \& Frei, 2016). System efficacy involve a person's belief that they are part of a system which offers protections. As most citizens do not know how to fight house fires or offer emergency medical care, they trust and rely on fire departments and emergency medical technicians for this type of efficacy. Response efficacy is 
the belief that a particular response or action will solve a problem or reduce damage (Witte et al., 2001). A person may believe that comprehensive health screenings can accurately isolate carriers of COVID-19 from interacting with the rest of the community—system efficacy—but may not believe that the system is fully effective for catching all cases; therefore, that person may choose to wear a mask and wash their hands regularly—self-efficacy and response efficacy.

\section{Community responses during and after}

disasters. Community response post-disaster has been studied intensely for more than a century. Since Prince's iconic study of the Halifax shipping disaster (1920), sociologists and scholars of crisis communication have demonstrated thoroughly that in the midst of disasters individuals tend to respond with prosocial behaviors of support and community care, often in emergent, spontaneous, unplanned efforts by individuals and groups (Pyle et al., 2019; Quarantelli \& Dynes, 1977; Waldman et al., 2017). In line with this body of research, early studies of responses to the COVID-19 pandemic suggest that individuals, households, and communities are experiencing solidarity. For example, Tierney (2020) notes the long-term trend demonstrated in pandemic and disaster literature that community members help those in need, donations to food banks increase, customers intensify support of local businesses, and local cultural institutions expand community engagement. Additional literature supports the important role of individual-level and community-level social capital during all phases of a disaster, including mitigation, preparedness, response and recovery (Meyer, 2018; Monteil et al., 2020). For example, in terms of disaster preparedness, establishing connections between agencies and establishing trust between residents and decision-makers are essential (Koh \& Cadigan, 2008). Similarly, social capital, in the form of networks, connections, and partnerships, are considered to be the "core engine" of the disaster recovery process (Aldrich, 2012, p. viii). In the context of food insecurity experienced after extreme weather events, social capital in the form of a lead actor who coordinates networks is especially important for rural communities (Chriest \& Niles, 2018).

\section{Considerations of Social Vulnerability in Crisis}

While no one is immune to the impact of threats and disasters, some population groups are more vulnerable to such impacts. Disparities of morbidity and mortality among vulnerable populations increase in times of disaster. Low-income residents with limited access to food are less likely to have the resources needed to secure food during- and post-disaster. In addition, residents with limited mobility (e.g., due to disabilities or no vehicle access) are less likely to evacuate, thus depending on local and emergency resources to provide shelter and food (Mundorf et al., 2015). In a study examining social cohesion following Superstorm Sandy, residents in low socioeconomic status neighborhoods had more confidence in recovery when there was more informal social control (Cagney et al., 2016). Higher levels of perceived neighborhood social cohesion can protect residents from food insecurity (Denney et al., 2017).

In order to meet other survival needs, lowincome families will often sacrifice food budgets (Frank et al., 2006, p. e1300). As a result, social capital seems to be a strong moderator of food insecurity. Community food resilience encompasses the social, economic, and physical environments to build the capacity to support local food systems (Tendall et al., 2015). Based on relevant research on social capital and low-income communities, we posited there would be high levels of community support in response to the multiple crises in Oconee County.

Rarely does a community experience an array of overlapping crises as described in the preceding literature. Thus, this exploratory, descriptive study examines a community impacted by multiple concurrent and consecutive crises, with the goal of understanding how a community experiencing food insecurity navigates multiple crises can serve as a model in order to inform resources, processes, and systems for supporting communities facing similar circumstances. To that end, we investigate the following research questions: (RQ1) To what extent did COVID-19 and the tornado impact local residents' access to food? (RQ2) What roles did community members play in supporting those affected by COVID-19 and the tornado? 


\section{Method}

\section{IRB Approval}

This study was reviewed and approved in May 2020 by the researchers' Institutional Review Board.

\section{Figure 1. COVID Case Rate per 1,000 by ZIP}

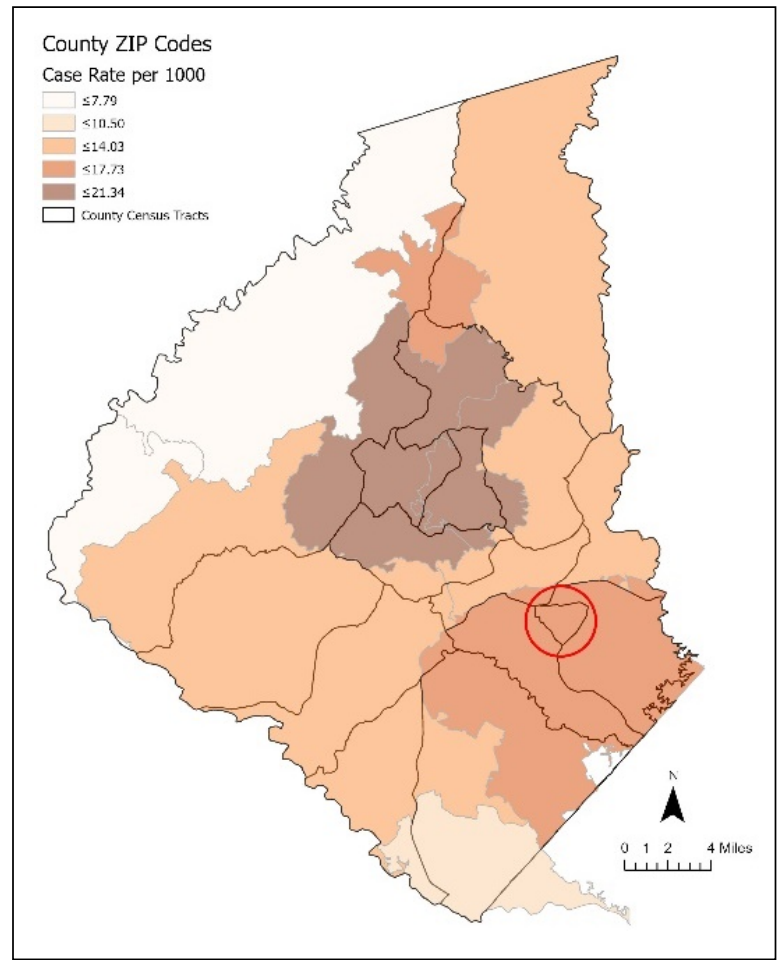

\section{Community Profile}

Data for this study were collected from residents of a single neighborhood in Oconee County, a rural county in the northwest corner of South Carolina that like many U.S. rural counties has experienced challenges since the onset of COVID-19 (Fretwell et al., 2020). Oconee County comprises 626 square miles with a population of 79,546 (U.S. Census Bureau, 2019). According to the U.S. Census Bureau (2019), Oconee County includes 87.5\% White, $6.6 \%$ Black, and $5.8 \%$ other races; $3.7 \%$ of the population is Hispanic. Just over one-fourth of county residents report earning a bachelor's degree or higher, and about $85 \%$ report an educational attainment level of at least 12 th grade. Oconee County's median household income is US $\$ 46,056$; $14.4 \%$ of the population lives in poverty (U.S. Census Bureau, 2019). The study targeted residents living in the under-resourced neighborhoods of Perry Hill, Dark Town, South Side, and Utica, as well as other small neighborhoods that are part of the Utica Mill Hill area, an unincorporated village adjacent to the city of Seneca in Oconee County.

Figures 1 through 5 illustrate the range of challenges that the community faces. Oconee County is largely rural and therefore did not see the immediate effects of COVID-19 until later in the summer. As of the end of September 2020, the Oconee County positive COVID case rate per 100,000 was
Figure 2. Inset of the Targeted Study Area that Included the Path of the EF-3 Tornado

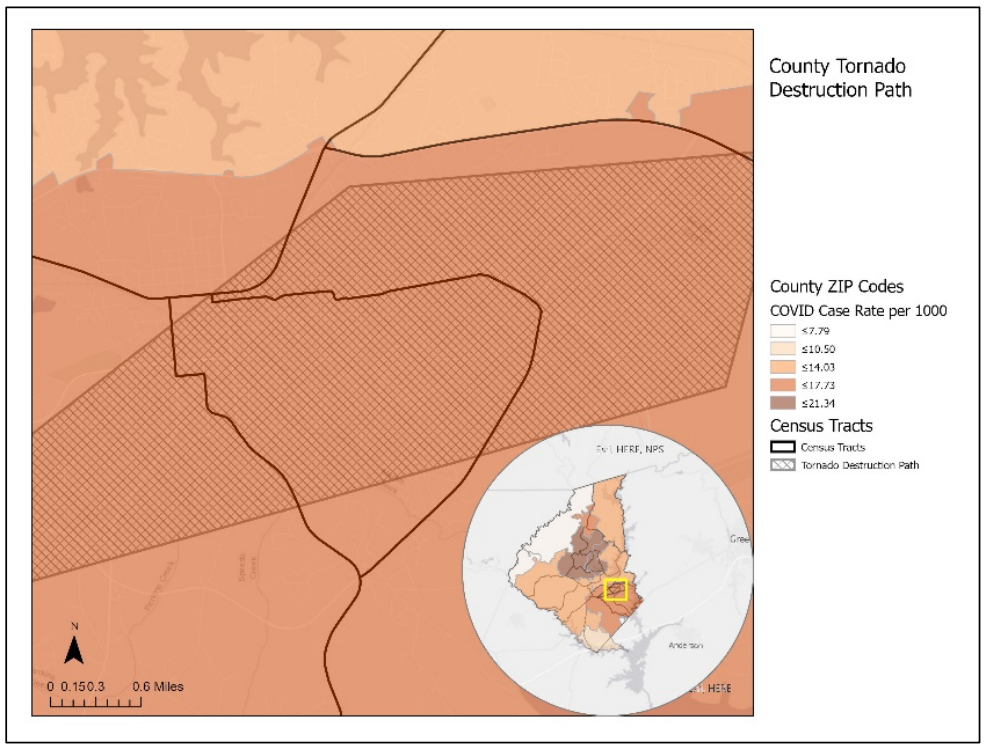

1,819 (Johns Hopkins University, 2020). COVID cases rates were available at the ZIP code level. As depicted in Figure 1, the COVID cases rate per 1000 residents was 17.73 in the ZIP code that includes the target area depicted by the red circle. While the ZIP code includes a larger area than the targeted area, Figure 2 identifies the path of the tornado destruction, which includes almost the entire census tract of the study. The most destructive path of the tornado encompasses nearly nine square miles.

The study area is one of the most socioeconomically vulnerable areas of the county. Figure 3 identifies the Social Vulnerability Index (SVI) that focuses on the household composition and disability in the census tracts. (An SVI 
closer to 1 indicates the most vulnerability.) The Agency for Toxic Substances and Disease Registry (ATSDR) developed the SVI as a measure to identify areas most at risk of adverse consequences prior to, during and following a disaster (Flanagan et al., 2018). The SVI provides guidance to disaster preparedness planning to prioritize areas for resource allocation. The SVI household composition and disability theme includes the following in its measure:

- Age over 65 years

- Age 17 years or younger

- Residents with a disability

- Single-parent households

The study area is also challenged by low household income (Figure 4) and lower life expectancy rates (Figure 5) compared to the rest of the state. The median household income for the study area was under US $\$ 28,402$, while the median income for the state was US\$52,306. The study area has the lowest life expectancy in the county, 72.4 years, compared to the state life expectancy of 79.1 years.

Figure 4. Median Household Income by Census Tract

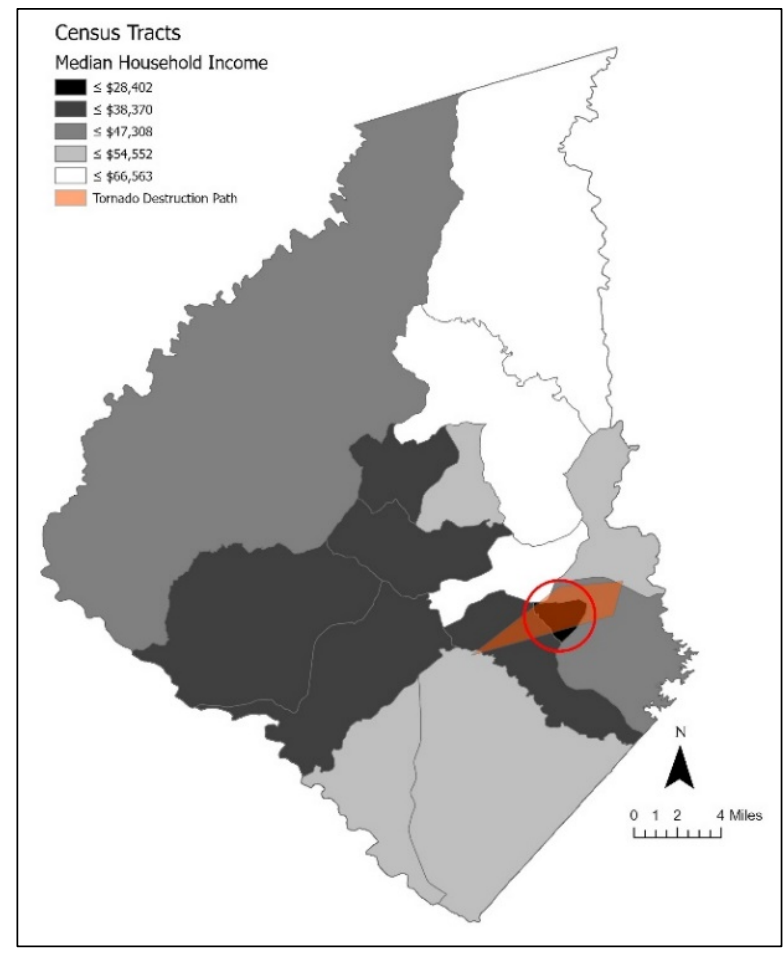

Figure 3. Social Vulnerability Index (Household Composition and Disability) by Census Tract

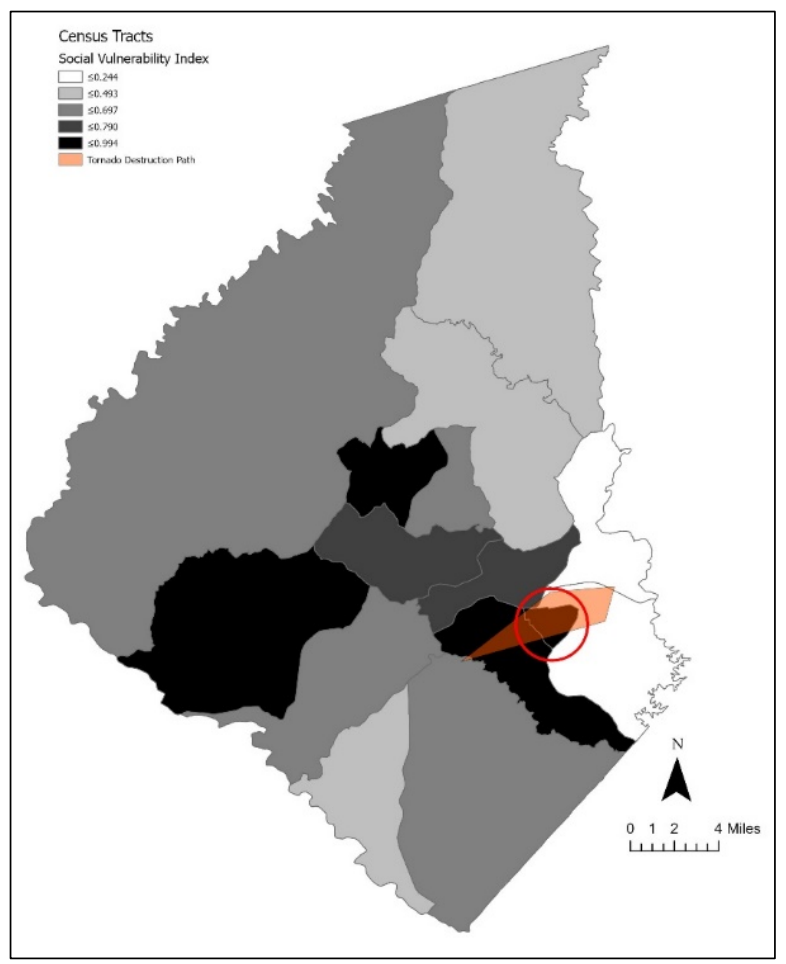

Figure 5. Life Expectancy by Census Tract

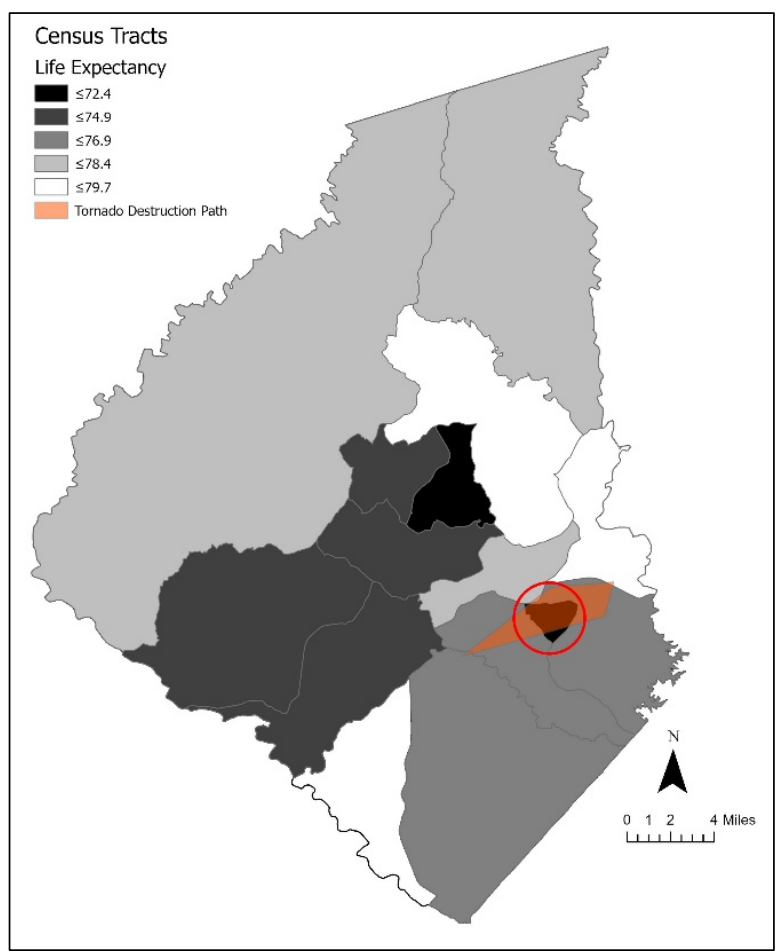




\section{Participants and Data Collection}

A qualitative research design explored how a community experiencing food insecurity navigates multiple concurrent health and environmental crises. Further, a postpositivist approach informed the study's critical realist perspective, through which reality (i.e., a participant's individual perceptions of their household's experience with food insecurity and other concurrent crises) was recognized as contextually dependent (Yin, 2016). A post-positivist theoretical frame was recognized as particularly appropriate for community-based (Yordy, 2012) food insecurity research (Beveridge et al., 2019). Within this frame, ethnographic methodolies (including in-depth interviews) are uniquely suited toward understanding a contextualized understanding of food insecurity (Beveridge et al., 2019).

Table 1. Description of Participants

\begin{tabular}{|c|c|c|}
\hline Characteristics & $\begin{array}{c}\text { Number of } \\
\text { participants }\end{array}$ & $\begin{array}{l}\text { Characteristics of } \\
\text { tornado-impacted } \\
\text { area (census tract) }\end{array}$ \\
\hline \multicolumn{3}{|l|}{ Gender } \\
\hline Male & 4 & $45.6 \%$ \\
\hline Female & 10 & $54.4 \%$ \\
\hline \multicolumn{3}{|l|}{ Race } \\
\hline White & 11 & $64.8 \%$ \\
\hline Black & 2 & $30.9 \%$ \\
\hline Other & 1 & $4.6 \%$ \\
\hline \multicolumn{3}{|l|}{ Education } \\
\hline Less than HS & 4 & $14.9 \%$ \\
\hline High school graduate or GED & 4 & $58.4 \%$ \\
\hline Some college, no degree & 4 & $20.7 \%$ \\
\hline Associate degree, 2-year degree, or technical school & 2 & $13.3 \%$ \\
\hline Bachelor's degree & 1 & $7.8 \%$ \\
\hline \multicolumn{3}{|l|}{ Household Income (US\$) } \\
\hline Unknown & 3 & $14.5 \%$ \\
\hline Less than $\$ 10,000$ & 2 & $8.2 \%$ \\
\hline$\$ 10,000-\$ 14,999$ & 3 & $16.6 \%$ \\
\hline$\$ 15,000-\$ 24,999$ & 3 & $13.6 \%$ \\
\hline$\$ 25,000-\$ 34,999$ & 1 & $16.9 \%$ \\
\hline$\$ 35,000-\$ 49,999$ & 0 & $14.6 \%$ \\
\hline$\$ 50,000-\$ 74,999$ & 2 & $15.6 \%$ \\
\hline \multicolumn{3}{|l|}{ Home Tenure } \\
\hline Unknown & 1 & $7.1 \%$ \\
\hline Rent & 8 & $35.8 \%$ \\
\hline Own & 5 & $57.1 \%$ \\
\hline \multicolumn{3}{|l|}{ Household Size } \\
\hline 1 & 7 & $46.4 \%$ \\
\hline $2-3$ & 2 & $36.1 \%$ \\
\hline $4-5$ & 5 & $17.5 \%$ \\
\hline
\end{tabular}

As part of a larger effort to address food insecurity within Oconee County, prior to data collection members of the research team established relationships with community leader, such as persons working in food systems, community development, elected office, governmental administration, and agriculture. To recruit participants into the current study following the onset of COVID-19 and the tornado- the two crises contextualizing "crisiswithin-a-crisis" in this study - an initial key informant helped the research team identify community leaders involved in the cleanup, food distribution, repairs and other critical responses soon after the tornado hit the communities. Through this informant, the research team engaged other community leaders (e.g., a church pastor, a tornado victim/ local volunteer, and a school system food service director), three of whom became additional key informants. These key informants identified Utica residents impacted by multiple crises and believed to be food insecure based on community demographics. This sampling approach, which combined purposeful and snowball sampling (Patton, 2002), allowed the research team to identify residents affected explicitly by the multiple crises in the targeted communities. Out of 37 community residents recruited using this process, 14 individual indepth interviews were completed $(\mathrm{RR}=37.8 \%)$. Reasons for non-participation included residents not answering their phone or having a phone number that had been disconnected when we attempted to reach them. Table 1 gives the full demographic details of the sample. Table 1 also includes comparisons to the census tract region of the sample. 
From mid-June through mid-September 2020, research team members conducted interviews using a semi-structured format. Interviews were conducted using mobile phones, and apps such as Rev.com recorded the interviews. All participants provided verbal consent. The interview protocol was designed to elicit information in critical areas associated with the study purpose and research questions, including how participants were faring financially, their experiences with food insecurity, COVID-19, the tornado, and their physical and emotional health. Interviews lasted an average of 45 minutes. Recordings were initially transcribed using Otter.ai and each transcript was verified by at least two research team associates. To ensure anonymity, each participant was given a pseudonym for the purpose of attributing quotes in the study.

\section{Data Analysis and Trustworthiness}

Transcripts were coded by a research team member using a deductive-inductive narrative analysis approach (Braun \& Clarke, 2006) informed by sensitizing concepts within the food insecurity literature yet cognizant of emergent themes. Before coding, the research team member reflected on personal demographics, experiences, knowledge, and potential sources of bias (i.e., positionality) that could influence how the data were interpreted (Bourke, 2014). Data from the transcripts were then coded to identify portions of text representing unique ideas or perceptions (Patton, 2002). After codes were identified, categories representing relationships across codes were developed. Finally, themes were developed based on a conceptual analysis of the constructed categories and representative quotes were identified for each theme. After the data analysis was completed, an independent audit of these materials was completed by another research team member not involved in the initial coding (Akkerman et al., 2008). The audit evaluated congruence between the raw data, data reduction and analysis artifacts (i.e., codes), and data reconstruction and interpretations (i.e., constructed categories, subthemes, and themes) (Cutcliffe \& McKenna, 2004). The audit process confirmed that the coders' interpretations accurately represented the participant's interview responses. Together these trustworthiness procedures (e.g., positionality, external audit) affirmed the trustworthiness of the data analysis process and interpretations.

\section{Results and Discussion}

The community was affected by a cascading series of crises (i.e., crisis-within-a-crisis), beginning with persistent household food insecurity and extending to include impacts of the onset of COVID-19 and the tornado on their families and community. Four themes emerged from the analyses that aligned with our research questions: crisis-within-a-crisis; community support; one region, two communities; and mental health in crisis. These themes are explored below.

\section{Crisis-within-a-Crisis}

Our first research question asked to what extent did COVID-19 and the tornado impact local residents' access to food. In the following section we outline the four crises facing the community. Then we describe reactions to the crises based on residents' circumstances and how they were personally affected by each crisis. Residents indicated varying degrees of concern about each of the crises facing the Mill Hill community; importantly, the degree of expressed concern seemed to be largely based on socio-economic status. The two-community dynamic emerged as one of our themes, as we discuss below.

Food insecurity was the first community crisis detected in participant responses. For many participants, food insecurity did not begin with the onset of the crises; rather, it was an ongoing part of daily life, already a "lingering crisis" prior to COVID-19 (DeVries \& Fitzpatrick, 2006). DeVries and Fitzpatrick describe lingering crises as comprising seven potential factors. The two that are most relevant to this crisis include a challenge to an organization or community recurring over time, and insufficient organizational responses to stakeholder concerns. (The structural dynamics that have resulted in this area being categorized as a food desert have not been addressed by local governmental or corporate entities.) Participants identified myriad ways to meet their food needs. Some relied on a family member's job or benefits or supplies from friends and neighbors. Many 
depended on disability payments or SNAP benefits, and all described benefitting from church food distribution ("food boxes"), food pantries, or food banks. As one participant said, "If it wasn't for people at the church, we wouldn't be able to have food or water or anything" (Jane).

While food sources varied from one participant to another, a major recurring issue was scarcity of healthy foods and increase in food costs during the crises, especially during the early stages of COVID-19 and then continuing in the aftermath of the tornado. Participants reported they could not find their "regular foods," and often had to resort to buying "unhealthy" or "junk" foods. They also reported cost increases in certain foods following the onset of COVID-19, which is consistent with national trends in increases in food costs (Mead et al., 2020). Participants reported they often had to make trade-offs: for example, having to choose between food or the electric bill. For some, a loss of infrastructure due to the tornado played an ongoing role in food quality and access. For example, some participants lost cooking implements, while others lost their entire kitchen. Other participants lost stored resources, such as food in their refrigerator and freezer due to extended loss of power to their homes. As a result of this infrastructure damage, residents were not able to access or prepare healthy, fresh, or diverse foods.

The second crisis that affected the community was COVID-19. As a result of the pandemic, participants expressed increased concerns about their family's health, access to transportation or resources, or access to online resources for work and school. Many participants also lost employment because of the pandemic. As one participant shared, "The virus is affecting people on the Mill Hill because they have either lost their job, or like one family, he just moved here and was planning on getting a job and then all of a sudden there wasn't any jobs" (Sarah). In addition, restrictions tied to COVID-19 also affected participants' access to health care or medication. For instance, some participants said that COVID-19 made it harder to acquire needed medications, and another said she was not making doctor appointments because of COVID-19 concerns. While some participants expressed concerns about COVID-19, concern was not universal. Despite clear community-level impacts from the virus, many participants shared they were not concerned about the virus, particularly within the context of other crises. For instance: "I mean, we had so much [tornado] cleanup help and friends showing up. And, you know, it just ... COVID sort of went out the window when you got 30 or 40 people working around your house trying to help you get stuff back together a little bit. You know?" (Stacy). Multiple participants shared the sentiment that after the tornado hit, COVID19 was no longer an issue of concern.

The third crisis that affected the community was the mid-April tornado, which damaged homes, businesses, and non-residential property on privately-owned land. One participant described the tornado's impact:

[My property will] never look the same again to me. But ... in a little bit things will grow back. That's the thing about trees and bushes and things. They grow back, you know, and I'm pretty optimistic about stuff and I just ... Okay you know, I'm not thrilled with it like it is. But I'm okay with it. Nobody in my family was hurt. One person in this whole tornado was killed. And if you saw all the damage around town, you would know that it was a miracle. (Stacy)

Some residents had to relocate temporarily due to the tornado, while others had to move away from Mill Hill permanently. The South side of the Seneca and Mill Hill communities was hardest hit, the section of Oconee County with the poorest residents and quite under-resourced to respond to the damage.

The fourth crisis facing the community was lack of clean water for many Mill Hill residents following the tornado: "We don't have any water at the moment still. So we can't really wash dishes. We're running low on tools, too.... We don't have the necessary tools to prepare other foods.... We don't have enough water to wash dishes" (Bill). Without consistent access to clean water, residents were faced with immediate health and hygiene concerns. Perhaps directly connected to lack of clean water, residents reported an ongoing hepatitis A 
outbreak in the community. The hepatitis virus can cause a highly contagious liver infection; symptoms often do not appear until weeks after contracting the virus. Participants reported feeling scared to see other people for fear of contracting hepatitis A. Risk of infectious diseases may increase following natural disasters when synergic factors align, including social and environmental conditions, displacement of populations, change in human conditions, and limited sanitation (Kouadio et al., 2012; McMichael, 2015). The transmission of infectious diseases can occur days, weeks or months following the disaster, often because of poor hygiene and lack of food, safe water, and adequate toilets (Kouadio et al., 2012).

Participants were concerned about the risk of hepatitis A exposure, but seemed largely unconcerned about contracting COVID-19. This finding is consistent with previous research on perceptions of risk, as by this time COVID had become a familiar risk, a part of every-day life. On the other hand, a hepatitis A outbreak was both novel and carried a social stigma and collective concern about the high risk of infection. Community members tend to become comfortable with familiar risks, such as COVID-19, while novel risks such as hepatitis A impose greater concern and fear (Kasperson et al., 1988).

These compounding crises left the community reeling and struggling to recover. In the following section, we explore how the community coalesced to respond to each crisis.

\section{Community Support}

Our second research question asked how community members supported other residents affected by COVID-19 and the tornado. A consistent and overriding theme throughout the interviews was that residents responded to the compounding crises by engaging in both emergent (spontaneous) and planned support of their fellow community members, similarly to what has been seen in other community-level responses to disaster (Quarantelli \& Dynes, 1977). Support was expressed in different ways.

First, community support was embedded in participants' reports about their own food needs. Perceptions of food insecurity were relative in comparison with others' needs. For example, participants with children reported little concern about having enough to eat as long as their children had enough food: "I make sure my children can eat, at any given point in the day that they want to. If they feel like they want to eat, they can" (Arthur). Second, a common idea was that, "I lost some things, but my neighbor lost more. Others have it worse than I do" (Reginald). The community, in this way, expressed great resilience (Anthony et al., 2019), an attitude that "things may be bad, but it could be worse, and things will get better." They are demonstrating hope for the future. Third, community members also worked hard to provide food to neighbors. Neighbor-helping-neighbor support happened via the individual efforts of community members, as well as through contributions from organizations and community groups (e.g., food pantries, churches, and food banks).

Fourth, following the tornado people helped clear and clean damaged property. Neighbors reached out to one another to offer support and help on an individual basis:

After the tornado hit, our area really came together. I mean, for the first few minutes when daylight hit that morning, everybody was just kind of shocked. And then all of a sudden, somebody is just like, we need to clear this tree off of this house, and it just kind of spiraled from there. And we've all been working together and helping each other. And, you know, it's been, we're all in it together. It happened to all of us. (Jill)

Another valuable aspect of the broader response efforts was the engagement of community organizations and groups. The community witnessed support from local churches and civic organizations. "They started bringing this ice and ice chests, water. They brought us plenty of foods, deodorants, and it was I mean, the people, I don't know who they was but they brought the Mill Hill a lot of stuff. I don't know who they were" (Sonia).

The second theme associated with Research Question 2 was that community members varied in the extent to which they accepted help from others. Many informants reflected on how much they 
rely on or need others. They described active acceptance and recognition of much-needed support with expressions of thankfulness and gratitude (as demonstrated in the previous quote from Sonia). Other community members relied on personal independence and rejected offers of support. For example, some participants indicated that they would not go to a food bank, despite a lack of resources. As Janell forcefully explained, "I'm the type of person, I don't go nowhere and ask. I will do without," capturing a sense of personal independence and self-efficacy evident with many of the participants.

Other participants indicated that although they were themselves experiencing certain challenges related to food insecurity, these difficulties were not as dire as those faced by some neighbors whom they felt called to help. For example, after explaining that he usually runs short of money at the end of the month to pay bills, Joseph said, "And then I still find myself, if I have a few extra dollars left at the end of the month, and I can help somebody else with it, I'll do it. . . It's cutting my own throat and I admit it is." Sarah, who was experiencing health issues unrelated to COVID-19, also felt an obligation to help community members: "Everybody's telling me 'you need to take time for yourself.' And, my viewpoint is I am, because I enjoy what I'm doing. . . . They think I'm not taking care of myself and I think I am.”

\section{One Region, Two Communities}

The third theme associated with Research Question \#2 involved differential experiences of the various crises, based on their familial and community resources and support. That is, there seemed to be two distinct communities in our interview pool, although the participants resided in the same geographic area. The first group is represented by the Mill Village. These residents were experiencing the multiple crises concurrently, but also had the fewest resources. This group was already facing food insecurity when the crises began and was also experiencing a housing crisis, with several landlords raising rent at the outset of COVID-19 or after the tornado. This group lost important housing infrastructure, lacks clean water, and in some cases faces foreclosure. This group also has a range of neigh- borhood concerns, including crime and drug use"Part of the neighborhood is really bad because there's a lot of drugs, meth heads walking around here, breaking into people's houses stealing. You can't keep nothing outside" (Sonia)—and challenges due to inadequate transportation. Many residents lack cars or access to transportation other than the bus system. Some residents are able to request a ride from a neighbor, friend, or family member, but then they rely on the schedules of others.

The second distinct group that emerged in the study findings is geographically within the Mill Hill community; however, these residents were not facing food insecurity before the multiple crises began. While they may face food insecurity now, they view it as a short-term, manageable concern. Food insecurity is simply not a regular part of life for this group. They also spoke more clearly of reliance on family and neighbors for support. While their lives have changed drastically, their daily needs can still be met. They may have lost income as a family, but they indicated that the losses are not overwhelming. While members of the other community reflected on having sufficient food for their children, members of this community were less concerned with availability of food for their children than they were about other concerns such as online learning:

Both of my children had a big issue with online learning. Teachers had never done that before. So you've got some teachers that were not computer friendly. ... And that's been a real issue with the online learning for both kids. (Sarah)

These results support recent research demonstrating that consistently food insecure households (i.e., households that were food insecure prior to COVID-19) were more likely to face challenges accessing food after the onset of the COVID-19 pandemic, as compared to newly food insecure households (Niles et al., 2020).

Residents also described changes in the way they spend time as a family. Members of this group reported spending more time together because of COVID-19; for example, "we play games a lot 
now." This was a positive change from what residents reported before the onset of COVID-19.

\section{Mental Health in Crisis}

The final theme that emerged in the findings was that the overlapping crises revealed a range of mental health challenges among community members, from pre-existing challenges exacerbated by the crises, to newly developed challenges. New challenges related to COVID-19 were generally tied to anxiety or depression primarily associated with isolation. For example, Jill described the new challenges that came after her spouse lost his job because of COVID-19; this couple was experiencing more conflict than before the pandemic: "My husband and I didn't pretty much argue before everything, but now we have gotten really well acquainted with that. So short tempers are definitely in the mix now." For other participants, the mental health challenges developed after the tornado:

It was an emotional thing, a stress thing. ... I've lived on this property 74 years. That's how old I am. So to look out my door and see all my trees gone. ... It's like losing a friend in the property that you had. (Stacy)

The tornado brought concerns about safe housing, clean water, and where meals were going to come from, which precipitated increased anxiety and depression. Some participants indicated they already had anxiety and depression, which worsened following the onset of the community crises. Paula stated, "I get depressed. ... I get anxiety attacks, especially from stress. When I'm stressed out, I start crying. [This has been going on] for almost three years." She described ways that lack of connection with others, food scarcity, and reduced transportation access had worsened her anxiety. Affected by an astounding series of compounding crises, people are feeling the strain of extended anxiety and the pressure of relentless uncertainty. A recent meta-analysis of the relationship between mental health and food insecurity reveals that food insecurity impacts the likelihood of experiencing stress or depression (Pourmotabbed et al., 2020). A recent study of food insecurity during the early stages of the COVID-19 pandemic revealed similar impacts of COVID-19 on mental health (Polsky \& Gilmour, 2020).

\section{Implications}

This study has implications for food systems, disaster research, and policy, and reinforces the im-

portance of informal social networks in addressing emergent food insecurity during and following disasters and overlapping crises. However, recovery has been slow for this community, as determined by the social vulnerability index, likely because of the community's level of vulnerability prior to the onset of COVID-19 and prior to the tornado.

Therefore, equitable preparedness planning should prioritize areas of highest vulnerability, incorporate social capital, and integrate dimensions of food security—availability, access, and stability (Kais \& Islam, 2016; Pingali et al., 2005).

\section{Community Food Systems}

When multiple crises strike, the absence of basic food needs becomes more acute. Response through community food systems is one mechanism communities can use to be more resilient. Community food systems development often emerges when community members come together to identify basic needs around food and production. Such initiatives provide a mechanism for greater food access, while strengthening communities in the process. Cornell University (1999) developed a primer on community food systems, which integrates food production, processing, distribution and consumption:

$[T]$ o enhance the environmental, economic, social and nutritional health of a particular place $\ldots$ by including the word "community" there is an emphasis on strengthening existing (or developing new) relationships between all components of the food system. This reflects a prescriptive approach to building a food system, one that holds sustainability-economic, environmental and social-as a long-term goal toward which a community strives. (Cornell Cooperative Extension, 1999, p. 1)

Opportunities in community food systems and food policy councils have begun to develop in 
Oconee County in response to the multiple and overlapping crises. Indeed, just two months before the tornado and a month prior to the early stages of COVID-19, Oconee County residents held a successful multi-sector, day-long Food Summit to build on the existing Comprehensive Plan for the county (Oconee County, 2019), and to organize around food sovereignty and food systems initiatives and to enhance and develop access to healthy affordable food for their community through food policy councils and community organizing. Examining the work of this and similar food policy council efforts in the county is the focus of future studies. In a post-COVID food economy, local food systems initiatives like those underway in Oconee County provide the greatest likelihood for sustainable long-term healthy food access for communities and meaningful social change in attaining food security. Local food systems also present an opportunity to build on community assets and strengths, such as the mutual help model that was so important to community members during the overlapping crises described in this paper.

Food policy councils that seek to develop and sustain community food systems initiatives have, at their core, localized responses to food production, distribution, and consumption (Broad-Leib, 2013). Community food systems focus on issues of equity and social justice, grounding this work in community concerns around sustainability, food security, and food access (Community Food Strategies, 2020). Community food policy councils are one way of bringing together stakeholders from across a community to improve access to healthy food by addressing food policies that influence food sourcing, cost, and availability through means that promote local agriculture and local economic development (Boden \& Hoover, 2018; Gupta et al., 2018). The Oconee County Comprehensive Plan recognizes local-level food insecurity and builds strategic goals around food systems planning, healthy food access incentives, and food policies into their county strategic visioning (Oconee County, 2019). These types of plans and community food systems are mechanisms that communities can use to become more resilient. Fostering resilience is vital for community success and renewal during and after a crisis.

\section{Emergent Behaviors in Crisis}

As we asked participants to discuss their disaster experiences, story after story included examples of community support and partnership. Yet the support people described was often developed and managed by word-of-mouth organizing or spontaneous supportive behaviors. These results support prior studies that emphasize the importance of social capital in post-disaster situations (Meyer, 2018; Monteil et al., 2020), although different forms of social capital can have varying post-disaster effects, both negative and positive (Montiel et al., 2020).

Scholars have called for emergency response organizations and municipalities to foster partnerships that can lead to stronger frameworks for coordinated response post-emergency; specifically, these calls emphasize the need to coordinate emergent aid and spontaneous volunteers to ensure that community support efforts are not inadvertently wasted (Pyle et al., 2018; Waldman et al., 2017). In addition to building disaster response infrastructure that accounts for emergent behaviors, more structured agents such as community groups, civic organizations, municipalities, and nonprofits must cultivate relationships and develop plans to facilitate unified post-disaster food system management.

\section{Limitations and Future Research}

In this paper, we report on the results of 14 indepth interviews with community members experiencing overlapping crises within a broader context of food insecurity. The study's contextualized postpositivist framing and use of in-depth interviews with community residents experiencing multiple crises (including COVID-19) were apropriatley positioned within the food insecurity literature (Beveridge et al., 2019; Ruszczyk et al., 2020). As such, this study sought to understand the experience of food insecurity in a way that was sensitive to participants' unique geographies and perspectives. Such a perspective grounded this study's methodology in a local contex (Wolfe et al., 2003). The study sample was predominantly white, which is a clear limitation in capturing the experiences of the full community. However, as is illustrated in Table 1, the sample tracks very closely with the racial composition of the community we examined. In addition to the demographic limitations of our 
sample, we must also acknowledge that the entire research team is white. This has undoubtedly affected our attempts to explore the dynamics of racial injustice in the community, as well as participant willingness to speak openly with us about these same issues. While the interviews explored questions related to participant perceptions of racial injustice, themes associated with racial injustice did not emerge related to the study research questions.

While the resulting narratives were rich in insights, the research could be enhanced with additional interviews from a more diverse population, a comparative framework (as noted above), and perspectives from other community stakeholders. To that end, our future research will integrate the results from our community focus groups in Oconee County and Hampton County, South Carolina which was also impacted by a tornado in mid-April 2020. The affected communities represent two contrasting cases regarding the role of local leaders in ameliorating food insecurity during the COVID-19 pandemic. We will also compare and contrast the results in Oconee County with research on food insecurity in the neighboring county of Pickens, where we are collecting qualitative data from individuals about the impact of COVID-19 on household-level food insecurity. Future research is also planned within South Carolina to examine how families in a variety of communities may experience food insecurity differ- ently across the calendar year (i.e., summer compared with non-summer), particularly for families with school-age children who may have reduced access to food when school is not in session.

\section{Conclusion}

This exploratory study examined a community's experiences with food insecurity in the context of a cascading series of crises. We sought to learn how residents navigate multiple crises in order to inform resources, processes, and systems that support communities facing similar circumstances. The study yielded substantial insights into the responses and perspectives of residents in under-resourced communities struck by a perfect storm of successive crises. This study provides a foundation for future studies to explore how communities can develop systems and policies to help protect their most vulnerable members, and provide data and findings that can inform community leaders and partners seeking to address food insecurity and community vulnerability in the future.

\section{Acknowledgments}

We would like to acknowledge and offer our deepest gratitude to the community members who shared their perspectives and stories in this study. We appreciate the key community members that served as trusted informants and helped us gain access to conduct this research. It would not have been possible without them.

\section{References}

Akkerman, S., Admiraal, W., Brekelmans, M., \& Oost, H. (2008). Auditing quality of research in social sciences. Quality \& Quantity, 42(2), 257-274. https://doi.org/10.1007/s11135-006-9044-4

Aldrich, D. P. (2012). Building resilience: Social capital in post-disaster recovery. University of Chicago Press.

Anthony, K. E., \& Sellnow, T. L. (2011). Information acquisition, perception, preference, and convergence by Gulf Coast residents in the aftermath of the Hurricane Katrina crisis. Argumentation and Advocacy, 48(2), 81-96. https://doi.org/10.1080/00028533.2011.11821756

Anthony, K. E., Venette, S. J., Pyle, A. S., Boatwright, B. C., \& Reif, C. E. (2019). The role of social media in enhancing risk communication and promoting community resilience in the midst of a disaster. In K. Bandana \& D. Cochran (Eds.), The role of risk communication in community resilience building (pp. 165-178). Routledge. https://doi.org/10.4324/9781315110042-13

Beveridge, L., Whitfield, S., Fraval, S., van Wijk, M., van Etten, J., Mercado, L., Hammond, J., Cortez, L. D., Suchini, J. G., \& Challinor, A. (2019). Experiences and drivers of food insecurity in Guatemala's dry corridor: Insights from the integration of ethnographic and household survey data. Frontiers in Sustainable Food Systems, 3(65), 65. https://doi.org/10.3389/fsufs.2019.00065 
Boden, S., \& Hoover, B. M. (2018). Food policy councils in the Mid-Atlantic: Working toward justice. Journal of Agriculture, Food Systems, and Community Development, 8(1), 39-52. https://doi.org/10.5304/jafscd.2018.081.002

Bourke, B. (2014). Positionality: Reflecting on the research process. The Qualitative Report, 19(33), 1-9. https://doi.org/10.46743/2160-3715/2014.1026

Broad-Leib, E. (2013). All (food) politics is local: Increasing food access through local government action. Harvard Law \& Policy Review, 7(321). https://papers.ssrn.com/sol3/papers.cfm?abstract_id=2339261

Cagney, K. A., Sterrett, D., Benz, J., \& Tompson, T. (2016). Social resources and community resilience in the wake of Superstorm Sandy. PLoS One, 11(8), e0160824. https://doi.org/10.1371/journal.pone.0160824

Chriest, A., \& Niles, M. (2018). The role of community social capital for food security following an extreme weather event. Journal of Rural Studies, 64, 80-90. https://doi.org/10.1016/j.jrurstud.2018.09.019

Coleman-Jensen, A., Rabbitt, M. P., Gregory, C. A., \& Singh, A. (2016). Household food security in the United States in 2015 (Economic Research Report No. 215). U.S. Department of Agriculture, Economic Research Service. https://www.ers.usda.gov/webdocs/publications/79761/err-215.pdf?v $=42636$

Community Food Strategies. (2020). Cultivating community: Bringing people together to create a more equitable food system. Community Food Strategies. https://communityfoodstrategies.com/

Cookey-Stower, K., Schwartz, M. B., \& Brownell, K. D. (2017). Food swamps predict obesity rates better than food deserts in the United States. International Journal of Environmental Research and Public Health, 14(11), 1366. https://doi.org/10.3390/ijerph14111366

Cornell Cooperative Extension. (1999). A primer on community food systems: Linking food, nutrition, and agriculture. Cornell Univerity, Cornell Cooperative Extension. https://d32ogoqmya1dw8.cloudfront.net/files/integrate/teaching_materials/food_supply/student_materials/ldqu oa primer community food.pdf

Cutcliffe, J. R., \& McKenna, H. P. (2004). Expert qualitative researchers and the use of audit trails. Journal of Advanced Nursing, 45(2), 126-133. https://doi.org/10.1046/j.1365-2648.2003.02874.x

Czeisler, M. É., Lane, R. I., Petrosky, E., Wiley, J. F., Christensen, A., Njai, R., ... \& Rajaratnam, S. M. (2020). Mental health, substance use, and suicidal ideation during the COVID-19 pandemic-United States, June 24-30, 2020. Morbidity and Mortality Weekly Report, 69(32), 1049-1057. https://doi.org/10.15585/mmwr.mm6932a1

Danhong C., Jaenicke, E. C., \& Volpe, R. J. (2016). Food environments and obesity: Household diet expenditure versus food deserts. American Journal of Public Health, 106(5), 881-888. https://doi.org/10.2105/AJPH.2016.303048

Denney, J. T., Kimbro, R. T., Heck, K., \& Cubbin, C. (2017). Social cohesion and food insecurity: Insights from the geographic research on wellbeing (GROW) study. Maternal and Child Health Journal, 21(2), 343-350. https://doi.org/10.1007/s10995-016-2119-5

Dev, D., \& Kabir, K. (2020). COVID-19 and food security in Bangladesh: A chance to look back 1on what is done and what can be done. Journal of Agriculture, Food Systems, and Community Development, 9(4), 143-145. https://doi.org/10.5304/jafscd.2020.094.008

DeVries, D. S., \& Fitzpatrick, K. R. (2006). Defining the characteristics of a lingering crisis: Lessons from the National Zoo. Public Relations Review, 32(2), 160-167. https://doi.org/10.1016/i.pubrev.2006.02.010

Feeding America. (2018). 2018 child county food insecurity in the United States. https://map.feedingamerica.org/county/2018/child

Flanagan, B. E., Hallisey, E. J., Adams, E., \& Lavery, A. (2018). Measuring community vulnerability to natural and anthropogenic hazards: The Centers for Disease Control and Prevention's Social Vulnerability Index. Journal of Environmental Health, 80(10), 34-36. https://www.ncbi.nlm.nih.gov/pubmed/32327766

Food, Conservation, and Energy Act of 2008. (2008). Public Law 110-246. Title VI, Sec. 7527. Study and report on food deserts. Government Printing Office. http://www.gpo.gov/fdsys/pkg/BILLS-110hr6124eh/pdf/BILLS-110hr6124eh.pdf.

Ford, J. L., \& Frei, S. S. (2016). Training for the unthinkable: Examining message characteristics on motivations to engage in an active-shooter response video. Communication Studies, 67(4), 438-454. https://doi.org/10.1080/10510974.2016.1196381 
Frank, D. A., Neault, N. B., Skalicky, A., Cook, J. T., Wilson, J. D., Levenson, S., . . Berkowitz, C. (2006). Heat or eat: The Low Income Home Energy Assistance Program and nutritional and health risks among children less than 3 years of age. Pediatrics, 118(5), e1293-e1302. https://doi.org/10.1542/peds.2005-2943

Fretwell, S., Bohatch, E., Bustos, J., Monk, J., \& Larson, L. S. (2020, April 19). Small, rural counties struggle with COVID-19 in ways big counties don't. The State. https://www.thestate.com/news/politics-government/article241832581.html\#storylink=cpy

Gupta, C., Campbell, D., Munden-Dixon, K., Sowerwine, J., Capps, S., Feenstra, G., \& Van Soelen Kim, J. (2018). Food policy councils and local governments: Creating effective collaboration for food ystems change. Journal of Agriculture, Food Systems, and Community Development, 8(Suppl. 2), 11-28. https://doi.org/10.5304/jafscd.2018.08B.006

Hossfeld, L., \& Rico Mendez, G. P., (2018). Looking for food: Food access, food insecurity, and the food environment in rural Mississippi, Family \& Community Health, 41(S2), S7-S14. https://doi.org/10.1097/FCH.0000000000000182

Johns Hopkins University. (2020). COVID-19 status report: Oconee, South Carolina [Dashboard Infographic]. https://bao.arcgis.com/covid-19/ihu/county/45073.html

Jorden, M. A., Rudman, S. L., Villarino, E., Hoferka, S., Patel, M. T., Bemis, K., ... \& Starita, L. M. (2020). Evidence for limited early spread of COVID-19 within the United States, January-February 2020. Morbidity and Mortality Weekly Report, 69(22), 680-684. https://doi.org/10.15585/mmwr.mm6922e1

Kais, S. M., \& Islam, M. S. (2016). Community capitals as community resilience to climate change: Conceptual connections. International Journal of Environmental Research and Public Health, 13(12), 1211. https://doi.org/10.3390/ijerph13121211

Kasperson, R. E., Renn, O., Slovic, P., Brown, H. S., Emel, J., Goble, R., ... \& Ratick, S. (1988). The social amplification of risk: A conceptual framework. Risk. Analysis, 8(2), 177-187. https://doi.org/10.1111/j.1539-6924.1988.tb01168.x

Koh, H. K., \& Cadigan, R. O. (2008). Disaster preparedness and social capital. In I. Kawachi, S. V. Subramanian, \& D. Kim (Eds.), Social capital and health (pp. 273-285). Springer. https://doi.org/10.1007/978-0-387-71311-3 13

Kouadio, I. K., Aljunid, S., Kamigaki, T., Hammad, K., \& Oshitani, H. (2012). Infectious diseases following natural disasters: Prevention and control measures. Expert Review in Anti-Infective Therapy, 10(1), 95-104. https://doi.org/10.1586/eri.11.155

Laborde, D., Martin, W., \& Vos, R. (2020). Poverty and food insecurity could grow dramatically as COVID-19 spreads. In J. Swinnen \& J. McDermott (Eds.), COVID-19 and global food Security (pp. 16-19). International Food Policy Research Institute. https://doi.org/10.2499/p15738coll2.133762 02

McMichael, A. J. (2015). Extreme weather events and infectious disease outbreaks. Virulence, 6(6), 543-547. https://doi.org/10.4161/21505594.2014.975022

Mead, D., Ransom, K., Reed, S. B., \& Sager, S. (2020, August). The impact of the COVID-19 pandemic on food price indexes and data collection. Monthly Labor Review, U.S. Bureau of Labor Statistics. https://doi.org/10.21916/mlr.2020.18

Meyer M. A. (2018) Social capital in disaster research. In H. Rodríguez, W. Donner, \& J. E. Trainor (Eds.), Handbook of disaster research (2nd ed.) (pp. 263-286). Springer. https://doi.org/10.1007/978-3-319-63254-4_14

Monteil, C., Simmons, P., \& Hicks, A. (2020). Post-disaster recovery and sociocultural change: Rethinking social capital development for the new social fabric. International Journal of Disaster Risk Reduction, 42, Article 101356. https://doi.org/10.1016/j.ijdrr.2019.101356

Mundorf, A. R., Willits-Smith, A., \& Rose, D. (2015). 10 Years later: Changes in food access disparities in New Orleans since Hurricane Katrina. Journal of Urban Health, 92(4), 605-610. https://doi.org/10.1007/s11524-015-9969-9

Niles, M. T., Bertmann, F., Belarmino, E. H., Wentworth, T., Biehl, E., \& Neff, R. (2020). The early food insecurity impacts of COVID-19. Nutrients, 12(7), 2096. https://doi.org/10.3390/nu12072096

Oconee County. (2019). Comprehensive Plan 2020. Chapter 8. Agricultural Element. Oconee County Planning. https://oconeesc.com/documents/community-dev/planning-zoning/comprehensive-plan/agriculture.pdf

Paton, D., Smith, L., \& Violanti, J. (2000). Disaster response: Risk, vulnerability and resilience. Disaster Prevention and Management, 9(3), 173-180. https://doi.org/10.1108/09653560010335068

Patton, M. Q. (2002). Qualitative evaluation and research methods ( $2^{\text {nd }}$ ed.). Sage. 
Pingali, P., Alinovi, L., \& Sutton, J. (2005). Food security in complex emergencies: Enhancing food system resilience. Disasters, 29(S1), S5-S24. https://doi.org/10.1111/j.0361-3666.2005.00282.x

Polsky, J. Y., \& Gilmour, H. (2020). Food insecurity and mental health during the COVID-19 pandemic. Health Reports, 31(12), 3-11. https://doi.org/10.25318/82-003-x202001200001-eng

Pourmotabbed, A., Moradi, S., Babaei, A., Ghavami, A., Mohammadi, H., Jalili, C., ... \& Miraghajani, M. (2020). Food insecurity and mental health: A systematic review and meta-analysis. Public Health Nutrition, 23(10), 1778-1790. https://doi.org/10.1017/S136898001900435X

Prince, S. H. (1920). Catastrophe and social change, based upon a sociological study of the Halifax disaster [Doctoral dissertation]. Columbia University, New York.

Pyle, A. S. (2018). Intercultural crisis communication: Examining the experiences of crisis sojourners. Journal of Applied Communication Research, 46(3), 388-407. https://doi.org/10.1080/00909882.2018.1467031

Pyle, A. S., Morgoch, M. L., \& Boatwright, B. C. (2019). SnowedOut Atlanta: Examining digital emergence on Facebook during a crisis. Journal of Contingencies and Crisis Management, 27(4), 414-422. https://doi.org/10.1111/1468-5973.12274

Quarantelli, E. L., \& Dynes, R. R. (1977). Response to social crisis and disaster. Annual Review of Sociology, 3, $23-49$. https://doi.org/10.1146/annurev.so.03.080177.000323

Ruszczyk, H. A., Rahman, M. F., Bracken, L. J., \& Sudha, S. (2020). Contextualizing the COVID-19 pandemic's impact on food security in two small cities in Bangladesh. Environment and Urbanization, 33(1), 239-254. https://doi.org/10.1177/0956247820965156

Schanzenbach, D. W., \& Tomeh, N. (2020, December 21). Household pulse survey results: Exploring seven key topics [Rapid Research Report]. Institute for Policy Research, Northwestern University. https://www.ipr.northwestern.edu/documents/reports/ipr-rapid-research-report-app- visualizes-economicindicators-21-december-2020.pdf

Schoonover, H. \& Muller, M. (2006). Food without thought: How U.S. farm policy contributes to obesity. Institute for Agriculture and Trade Policy. https://www.iatp.org/documents/food-without-thought-how-us-farm-policy-contributes-obesity

Sommerfeld, R. (2015, Feb. 22). May 4, 2007 tornado devastates Greensburg. KSN.com. https://www.ksn.com/news/may-4-2007-tornado-devastates-greensburg/

Tarasuk, V., Cheng, J., de Oliveira, C., Dachner, N., Gundersen, C., \& Kurdyak, P. (2015). Association between household food insecurity and annual health care costs. Canadian Medical Association Journal, 187(14), E429-E436. https://doi.org/10.1503/cmaj.150234

Tendall, D. M., Joerin, J., Kopainsky, B., Edwards, P., Shreck, A., Le, Q. B., ... Six, J. (2015). Food system resilience: Defining the concept. Global Food Security, 6, 17-23. https://doi.org/10.1016/j.gfs.2015.08.001

Tierney, K. J. (2020, May 21). Pandemic and disaster: Insights from seventy years of social science disaster research. Items: Insights from the SocialSciences [Digital Forum]. Social Science Research Council. https://items.ssrc.org/covid-19-and-the-social-sciences/disaster-studies/pandemic-and-disaster-insights-fromseventy-years-of-social-science-disaster-research/

Ulmer, R. R., Sellnow, T. L., \& Seeger, M. W. (2019). Effective crisis communication: Moving from crisis to opportunity (4th ed.). Sage.

U.S. Census Bureau. (2019). QuickFacts: Oconee County, South Carolina. U.S. Census Bureau, U.S. Department of Commerce. https://www.census.gov/quickfacts/oconeecountysouthcarolina

U.S. Department of Agriculture, Economic Research Service. (2019). Definitions of food security. https://www.ers.usda.gov/topics/food-nutrition-assistance/food-security-in-the-us/definitions-of-foodsecurity.aspx

U.S. Department of Agriculture, Economic Research Service. (2020). Documentation. Overview of surveys. Current population survey food security supplement. https://www.ers.usda.gov/data-products/food-security-in-the-united-states/documentation.aspx

Veil, S. R., \& Bishop, B. W. (2014). Opportunities and challenges for public libraries to enhance community resilience. Risk. Analysis, 34(4), 721-734. https://doi.org/10.1111/risa.12130 
Waldman, S., Yumagulova, L., Mackwani, Z., Benson, C., \& Stone, J. T. (2017). Canadian citizens volunteering in disasters: From emergence to networked governance. Journal of Contingencies and Crisis Management, 26 (3), $394-402$. https://doi.org/10.1111/1468-5973.12206

Witte, K., Meyer, G., \& Martell, D. (2001). Effective health risk messages: A step-by-step guide. Sage.

Wolfe, W. S., Frongillo, E. A., \& Valois, P. (2003). Understanding the experience of food insecurity by elders suggests ways to improve its measurement. The Journal of Nutrition, 133(9), 2762-2769. https://doi.org/10.1093/jn/133.9.2762

Yin, R. K. (2016). Qualitative research from start to finish (2 ${ }^{\text {nd }} \mathrm{Ed}$.). Guilford.

Yordy, C. (2012). Rigour in methods and evaluation for community engagement (Working Paper Series). Carleton University. https://doi.org/10.22215/cfice-2012-01 